\title{
Directed evolution and secretory expression of xylose isomerase for improved utilisation of xylose in Saccharomyces cerevisiae
}

\author{
Jung-Hoon Bae ${ }^{1 \dagger}$, Mi-Jin Kim ${ }^{1 \dagger}$, Bong Hyun Sung ${ }^{1}$, Yong-Su Jin² and Jung-Hoon Sohn ${ }^{1,3^{*}}$ (D)
}

\begin{abstract}
Background: Xylose contained in lignocellulosic biomass is an attractive carbon substrate for economically viable conversion to bioethanol. Extensive research has been conducted on xylose fermentation using recombinant Saccharomyces cerevisiae expressing xylose isomerase $(\mathrm{XI})$ and xylose reductase/xylitol dehydrogenase (XR/XDH) pathways along with the introduction of a xylose transporter and amplification of the downstream pathway. However, the low utilization of xylose in the presence of glucose, due to the varying preference for cellular uptake, is a lingering challenge. Studies so far have mainly focused on xylose utilization inside the cells, but there have been little trials on the conversion of xylose to xylulose by cell before uptake. We hypothesized that the extracellular conversion of xylose to xylulose before uptake would facilitate better utilization of xylose even in the presence of glucose. To verify this, XI from Piromyces sp. was engineered and hyper-secreted in S. cerevisiae for the extracellular conversion of xylose to xylulose.
\end{abstract}

Results: The optimal pH of XI was lowered from 7.0 to 5.0 by directed evolution to ensure its high activity under the acidic conditions used for yeast fermentation, and hyper-secretion of an engineered XI-76 mutant (E56A and I252M) was accomplished by employing target protein-specific translational fusion partners. The purified XI-76 showed twofold higher activity than that of the wild type at pH 5. The secretory expression of XI-76 in the previously developed xylose utilizing yeast strain, SR8 increased xylose consumption and ethanol production by approximately $7-20 \%$ and $15-20 \%$ in xylose fermentation and glucose and xylose co-fermentation, respectively.

Conclusions: Isomerisation of xylose to xylulose before uptake using extracellular XI was found to be effective in xylose fermentation or glucose/xylose co-fermentation. This suggested that glucose competed less with xylulose than with xylose for uptake by the cell. Consequently, the engineered XI secretion system constructed in this study can pave the way for simultaneous utilization of $\mathrm{C} 5 / \mathrm{C} 6$ sugars from the sustainable lignocellulosic biomass.

Keywords: Xylose, Xylose isomerase, Secretion, Saccharomyces cerevisiae, Co-fermentation

*Correspondence: sohn4090@kribb.re.kr

†Jung-Hoon Bae and Mi-Jin Kim contributed equally to this study ${ }^{1}$ Synthetic Biology and Bioengineering Research Center, Korea Research Institute of Bioscience and Biotechnology (KRIBB), 125 Gwahak-ro, Yuseong-gu, Daejeon 34141, Republic of Korea

Full list of author information is available at the end of the article

\section{Background}

Utilisation of lignocellulosic biomass for the production of bio-based energy is an urgent issue to identify sustainable alternatives to conventional fossil fuels. Lignocellulosic biomass has been considered the most abundant carbohydrate source for bioethanol production, and it does not compete with food resources [1]. Most early studies on the utilisation of lignocellulosic biomass have focused on the fermentation of glucose derived from original author(s) and the source, provide a link to the Creative Commons licence, and indicate if changes were made. The images or other third party material in this article are included in the article's Creative Commons licence, unless indicated otherwise in a credit line to the material. If material is not included in the article's Creative Commons licence and your intended use is not permitted by statutory regulation or exceeds the permitted use, you will need to obtain permission directly from the copyright holder. To view a copy of this licence, visit http://creativecommons.org/licenses/by/4.0/. The Creative Commons Public Domain Dedication waiver (http://creativeco mmons.org/publicdomain/zero/1.0/) applies to the data made available in this article, unless otherwise stated in a credit line to the data. 
cellulose, which can be easily converted to ethanol. As lignocellulosic biomass contains a significant amount of hemicellulose (up to $25-50 \%$ of the total dry weight), there is a need to develop a cost-effective bioethanol production process that efficiently utilises xylose, which is the most abundant pentose sugar in hemicellulose $[2,3]$.

Saccharomyces cerevisiae has been an attractive industrial workhorse for bioethanol production owing to high ethanol yields and its general robustness to environmental stresses. However, xylose is not an easy substrate for S. cerevisiae due to the low uptake rate and low catabolic activity for xylose. Although some yeasts, such as Scheffersomyces stipitis, can utilise xylose, their ethanol productivity and stress tolerance were considerably lower than those of S. cerevisiae [4]. Therefore, numerous studies have focused on metabolic engineering for establishment and improvement of xylose fermentation in $S$. cerevisiae (reviewed in [5]).

Xylose assimilation is generally achieved by two different pathways. In most xylose-utilizing eukaryotes, xylose is converted into xylulose via xylitol by NADPHdependent xylose reductase (XR) followed by an $\mathrm{NAD}^{+}$-dependent xylitol dehydrogenase (XDH) [6-8]. In contrast, bacteria directly convert xylose to xylulose by xylose isomerase (XI) [9-12]. The product of both pathways, xylulose is phosphorylated by xylulose kinase (XK) and then enters into the pentose phosphate pathway for conversion to ethanol. Comparison of both pathways in different $S$. cerevisiae strains using various substrates [13-16] revealed that the XI pathway always gave a higher ethanol yield than the XR/XDH pathway. When both pathways were introduced into a single $S$. cerevisiae strain, a synergistic effect on xylose fermentation was observed [17, 18]. In addition, introduction of a xylose transporter or amplification of the downstream pathway has also proven to be beneficial $[19,20]$.

Therefore, for the development of xylose-fermenting $S$. cerevisiae, the inclusion of both XI and XR/XDH pathways and various other modifications into a single strain is favourable.

$\mathrm{XR} / \mathrm{XDH}$ should be expressed in the cytosol due to the requirement for nicotinamide cofactors. Though XI is also a cytosolic enzyme, its activity is independent of cofactors. XI is inhibited by xylitol, a by-product of the $\mathrm{XR} / \mathrm{XDH}$ pathway. Therefore, XI can be expressed extracellularly for xylose-fermenting yeast to escape from xylitol inhibition and to convert xylose to xylulose before uptake. Because S. cerevisiae takes up xylulose more rapidly than xylose [21], XI was used in immobilized form for simultaneous isomerization and fermentation (SIF) of xylose [22, 23], or expressed on the cell surface of $S$. cerevisiae for the conversion of xylose to xylulose outside the cell [24]. Nevertheless, there have been no follow-up studies, because SIF requires a large amount of purified $\mathrm{XI}$ for immobilization, and a surface display system is not optimal for the functional expression of XI as it requires multimerization for its activity [25]. Therefore, complete secretion of XI by the yeast itself could be more advantageous than the use of immobilised or surface-displayed XI for xylose assimilation.

In this study, we developed a recombinant S. cerevisiae that secretes a $\mathrm{pH}$-optimized XI capable of continuously converting xylose to xylulose in the media before cell uptake during fermentation. For this purpose, $x y l A$ of Piromyces sp. E2 [26] was engineered to shift its $\mathrm{pH}$ optimum from 7.0 to 5.0 to fit the optimal conditions of yeast fermentation. Then, the engineered XI was hypersecreted into the culture medium by employing target protein-specific translational fusion partners (TFP) selected from the yeast genome-wide secretion leader library [27]. By addition of the XI secretion system developed in this study to the previously developed $S$. cerevisiae SR8 strain engineered with the $\mathrm{XR} / \mathrm{XDH}$ pathway [28], ethanol could be effectively produced not only in xylose single fermentation but also in xylose/glucose co-fermentation.

\section{Results \\ Construction of recombinant S. cerevisiae secreting XI from Piromyces sp. E2}

Since the $x y l A$ gene from Piromyces sp. E2 was the first eukaryotic XI functionally expressed in S. cerevisiae, we selected this gene for secretory expression in S. cerevisiae. Given that XI is a cytosolic protein, an efficient signal peptide is required to direct this protein into the extracellular medium. The $x y l A$ gene was expressed under the control of GAL10 promoter on a URA3 selectable multicopy vector using pre-selected 24 types of TFPs that are frequently screened for secretion of recombinant proteins [29-31]. The TFP vectors were designed to include the Kexin processing site at the junction between the TFP and $x y l A$ to secrete the correctly processed XI. Recombinant strains were directly constructed by co-transformation of S. cerevisiae 2805 $\Delta$ gal80 with linearized TFP vectors and $x y l A$ gene flanked with linker and terminator sequences (Additional file 1: Fig. S1). After cultivation of transformants, the culture supernatants were analysed by SDS-PAGE and western blotting to compare the amount of XI secreted by the specific TFPs. Most of the TFPs secreted correctly processed XI $(50 \mathrm{kDa})$ through Kexin processing but showed different secretion levels (Additional file 1: Fig. S2). Among the 24 TFPs, TFP3, 8, 13, 14, 19 , and 20 showed remarkable capacity for extracellular production of recombinant XI (Additional file 1: Fig. S2). Three independent colonies were then randomly selected from each transformant and cultivated in YPDX medium 
containing $1 \%$ glucose and $1 \%$ xylose. The culture supernatant of each transformant was analysed by SDS-PAGE and western blotting (Fig. 1a, b). After $40 \mathrm{~h}$ of cultivation, the amount of xylose consumed by each transformant was compared (Fig. 1c). The amounts of secreted XI were proportional to the amounts of consumed xylose.

TFP3 containing 117 amino acids (aa) from the N-terminus of cell wall-associated mannoprotein CIS3 (alias PIR4) showed the highest capacity for secretion of XI, and a transformant expressing TFP3-XI consumed the highest amount of xylose $(5.8 \mathrm{~g} / \mathrm{L})$.

\section{Comparison of different types of XI expression}

In yeast, mating factor alpha (MF $\alpha)$ pre-pro peptide of $S$. cerevisiae has been generally used for secretion of recombinant proteins because of its outstanding qualifications
[32]. To confirm the secretion-enhancing effect of TFP3, growth and xylose consumption of transformants expressing TFP3-XI, MF $\alpha$-XI, and intra-XI (intracellular XI) were compared in YPX medium containing $2 \%$ xylose as a sole carbon source, and the extracellular and intracellular fractions of each transformant were analysed after $72 \mathrm{~h}$ of cultivation (Fig. 2). Each transformant expressing TFP3-XI and intra-XI showed $40 \%$ and $80 \%$ of enhanced growth and xylose consumption compared to those of the transformant expressing MF $\alpha$-XI at the end of fermentation (Fig. 2a, b). The amount and activity of secreted XI using TFP3 were twice those achieved using MFo signal peptide (Fig. 2c, d). Since the XI from Piromyces sp. E2 is a cytosolic protein, no XI protein was detected in the extracellular fraction of a transformant expressing intra-XI, but the total XI activity (sum

$\mathbf{a}$

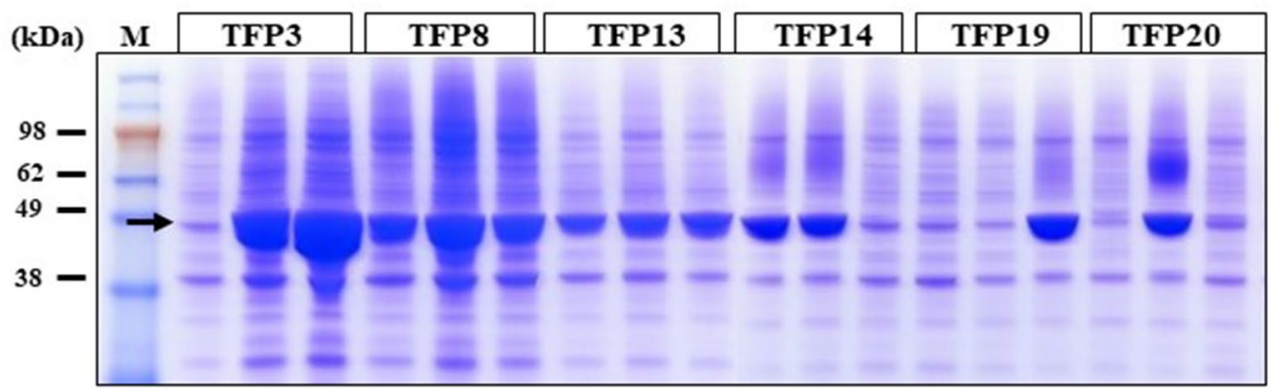

b

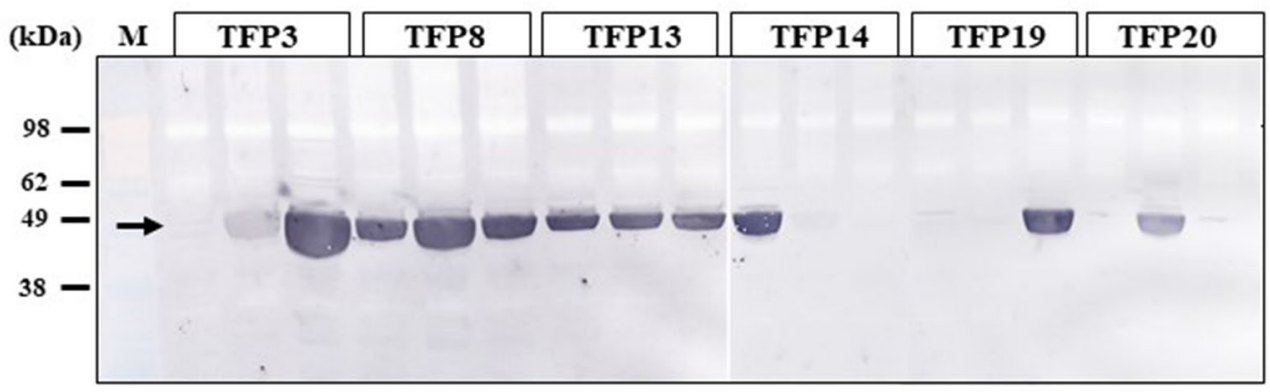

c

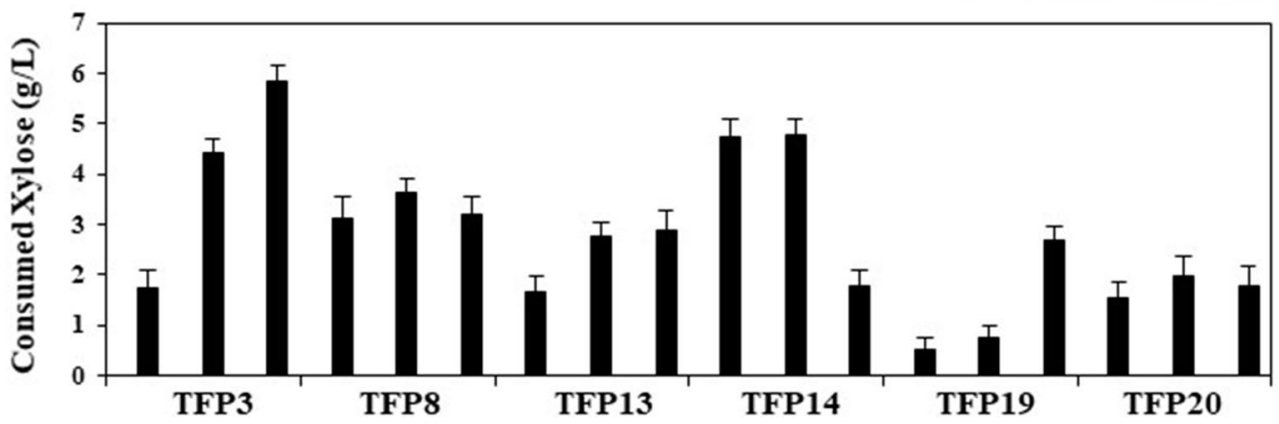

Fig. 1 Selection of optimal translational fusion partner (TFP) for xylose isomerase (xyIA) secretion in S. cerevisiae. a SDS-PAGE and $\mathbf{b}$ western blot analysis using anti-6xHIS antibody against xylA secreted by the TFP system. $\mathbf{c}$ Amount of xylose consumed after $40 \mathrm{~h}$ cultivation in YPDX medium. The xylA protein band is indicated by an arrow. M: protein size marker 


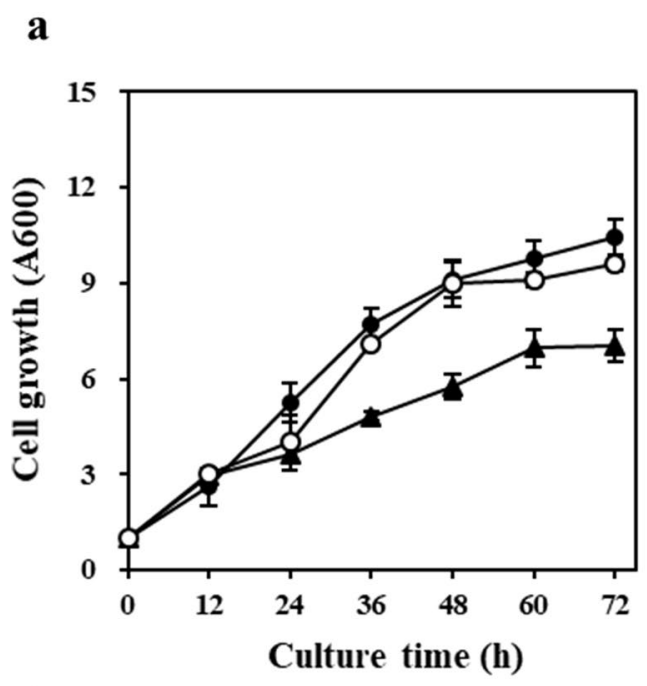

c

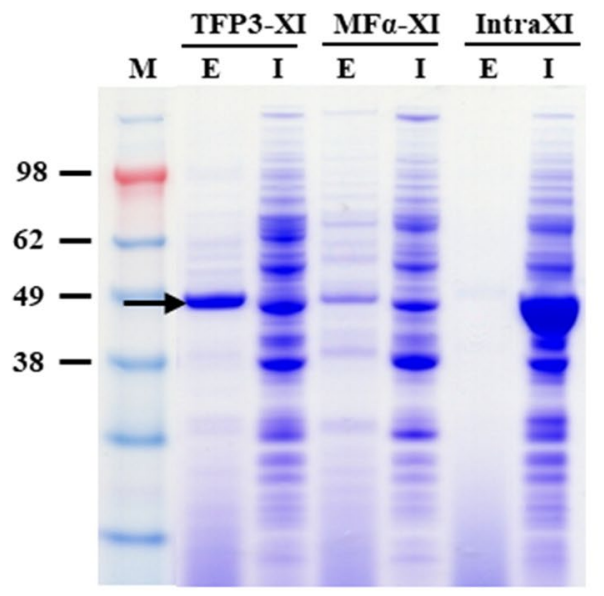

E: Extracellular, I: Intracellular

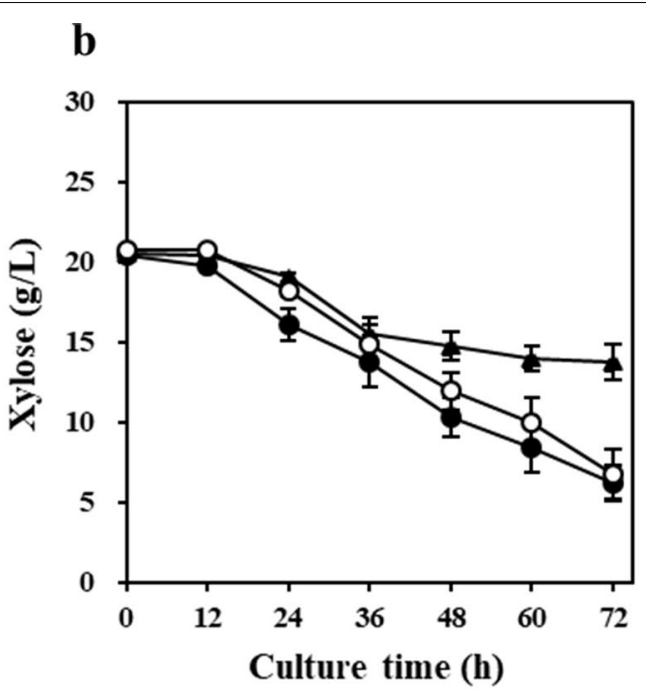

d

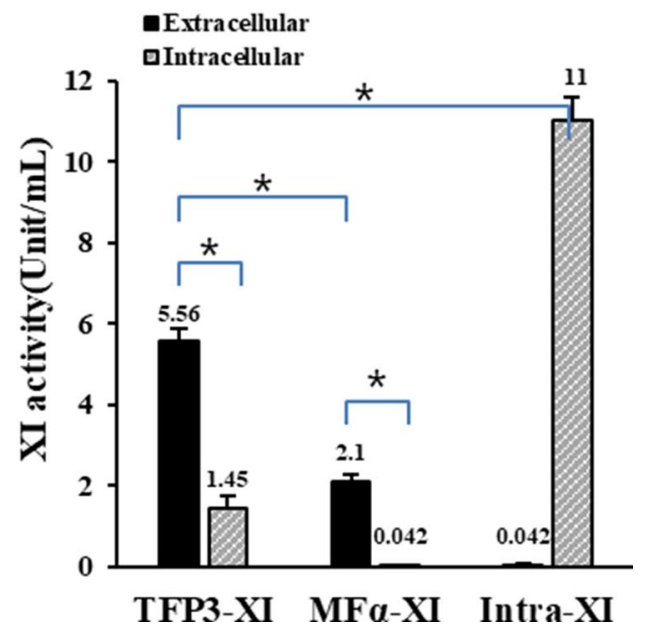

Fig. 2 Growth and xylose consumption of three xylose-assimilating strains in YPX medium containing 2\% xylose. a Cell growth, b xylose consumption, $\mathbf{c}$ SDS-PAGE and $\mathbf{d} \mathrm{XI}$ activity of the extracellular and intracellular fractions of each strain after $72 \mathrm{~h}$ cultivation in YPX medium. The xylA protein band is indicated by an arrow. Mean values and standard deviations of triplicates are shown. ${ }^{*} p<0.03$. Symbols: TFP3-XI (-), MFa-XI

(A), Intra-XI (O)

of intra and extracellular activity) was higher than that of the transformant expressing TFP3-XI (Fig. 2d). Despite showing the highest total XI activity, the growth and xylose consumption of the intra-XI expressing strain were similar to those of the strain expressing TFP3XI. These results imply that extracellular conversion of xylose is more desirable than intracellular conversion for xylose utilization.

\section{Characterisation of secretory expressed XI}

For the secretory production of XI, fed-batch fermentation of recombinant S. cerevisiae $2805 \Delta$ gal80 strains expressing TFP3-XI was performed, and recombinant
XI was purified from the culture broth using Ni-affinity chromatography. The optimum temperature of the purified XI was analysed in $50 \mathrm{mM}$ Tris- $\mathrm{HCl}$ buffer $(\mathrm{pH} 7.5)$ and the optimum $\mathrm{pH}$ was analysed at $60{ }^{\circ} \mathrm{C}$ (Fig. 3). The activity of purified XI increased steadily with an increase in temperature until $60{ }^{\circ} \mathrm{C}$ and then decreased rapidly. The purified XI showed narrow optimum $\mathrm{pH}$ at neutral condition. As XI is a multimeric enzyme requiring two bivalent metal ions, the effect of various metal ions on the XI activity was confirmed. Contrary to the XI expressed in $E$. coli [33], the XI produced in yeast showed a slightly higher preference for $\mathrm{Mg}^{2+}$ than $\mathrm{Mn}^{2+}$ (Fig. 3c). The two metal ions are involved in binding of the substrate and 
a

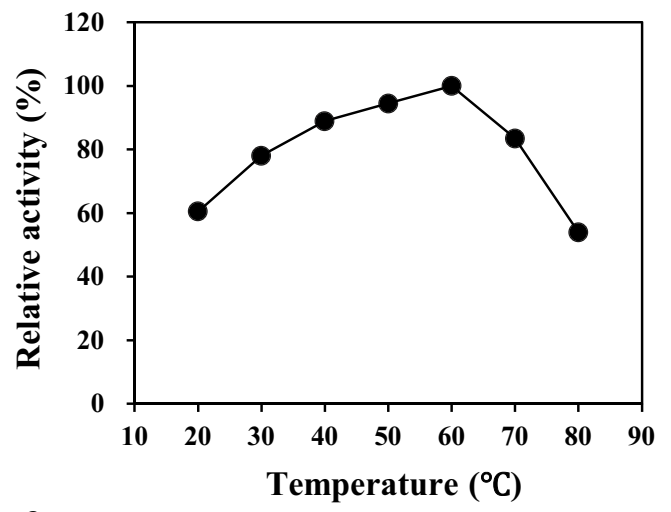

c

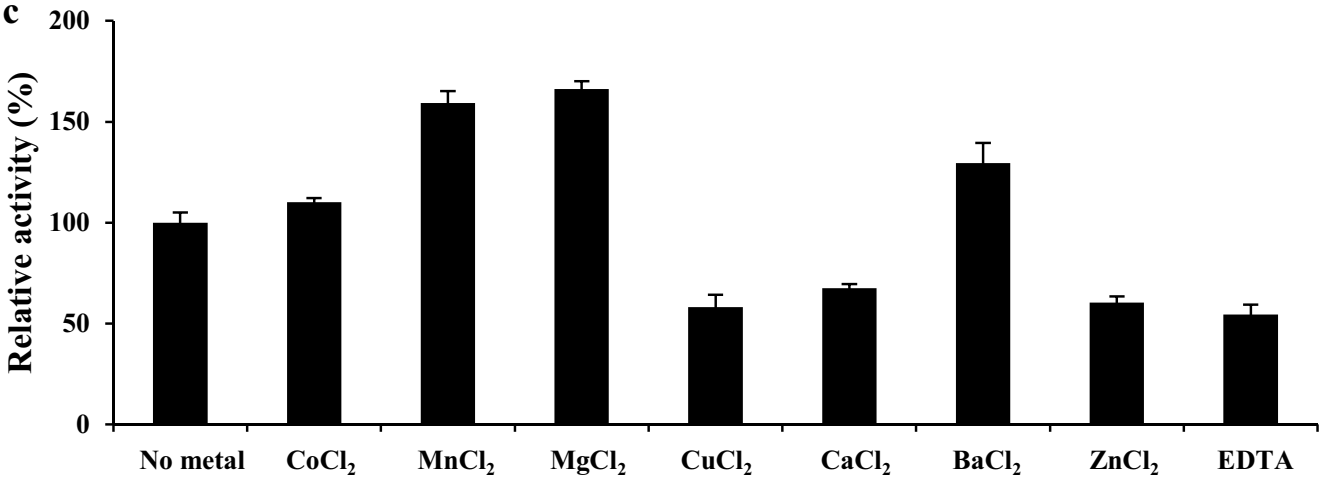

b

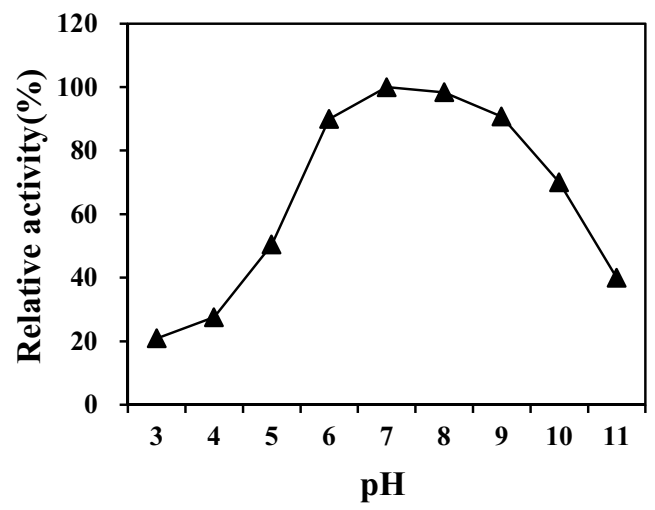

Fig. 3 Characterization of extracellularly produced recombinant xylose isomerase. Effects of $\mathbf{a}$ temperature, $\mathbf{b} \mathrm{pH}$, and $\mathbf{c}$ metal ions on XI activity were determined by quantitative analysis of xylulose with HPLC

the isomerisation reaction [34]. Therefore, optimum concentrations of metal ions required for the efficient utilisation of xylose were determined by comparing growth of S. cerevisiae $2805 \Delta$ gal80 strains expressing TFP3-XI in YPX medium containing various concentrations of $\mathrm{MgCl}_{2}$ and $\mathrm{MnCl}_{2}$ (Additional file 1: Fig. S3). The S. cerevisiae transformant showed saturated growth at $0.5 \mathrm{mM}$ $\mathrm{MnCl}_{2}$ and highest growth at $20 \mathrm{mM} \mathrm{MgCl}$. When these two ions were used simultaneously, growth was further increased by approximately $30 \%$ compared to the case where $\mathrm{MnCl}_{2}$ was used alone. Therefore, $0.5 \mathrm{mM} \mathrm{MnCl}_{2}$ and $20 \mathrm{mM} \mathrm{MgCl}_{2}$ were added to the medium hereafter.

\section{Insufficient conversion of xylose to xylulose by secreted XI}

To assess the consumption of xylose in the presence of glucose, transformants expressing TFP3-XI and intraXI were cultured in flasks containing YPDX medium (2\% glucose and $2 \%$ xylose) for $84 \mathrm{~h}$, and growth and the amount of xylose consumed were analysed (Fig. 4). After $36 \mathrm{~h}$ of fermentation, the TFP3-XI strain showed enhanced xylose consumption and growth compared to the intra-XI strain (Fig. 4). However, to our disappointment, the xylose was almost not used in the early part

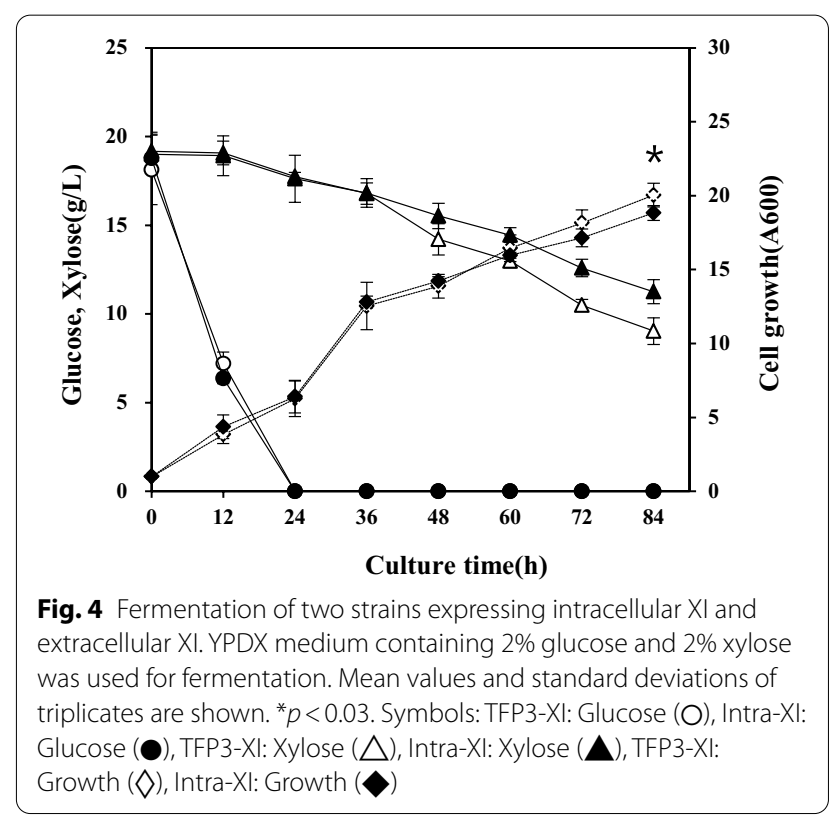


of fermentation when glucose was also present. After glucose was exhausted, both strains began to use xylose slowly. This result implies that extracellular conversion of xylose to xylulose was not sufficient to support growth, or the uptake of converted xylulose was still hindered by glucose. To validate the simultaneous utilisation of xylulose and glucose, S. cerevisiae $2805 \Delta$ gal 80 and S. cerevisiae 2805 4 gal80, XKS1 strains were cultured in YPDXu medium ( $2 \%$ glucose and $2 \%$ xylulose) for $60 \mathrm{~h}$ under ethanol fermentation conditions. Gal80 mutant was used for the constitutive expression of XI under the control of a strong GAL10 promoter without the induction of galactose [35]. Glucose utilisation was similar in both strains, but xylulose utilisation was dependent on the overexpression of XK. S. cerevisiae $2805 \Delta$ gal80 strain utilised xylulose after exhaustion of glucose, while $S$. cerevisiae 2805 gal80, XKS1 strain efficiently utilised xylulose and glucose at similar rates, albeit slightly delayed (Additional file 1: Fig. S4). Consequently, the slow utilization of xylose (Fig. 4), can be mainly attributed to the inefficient extracellular conversion of xylose to xylulose and weak xylulose assimilation of the host strain. Therefore, it is necessary to increase the extracellular activity of XI and to reinforce the downstream pathway of xylulose utilization.

\section{Directed evolution of $\mathrm{XI}$ to generate low $\mathrm{pH}$-optimized variant}

As the native XI showed only $50 \%$ activity under the culture conditions of yeast ( $\mathrm{pH}$ 5.0) compared to that at its optimal condition (pH 7.0) (Fig. 3b), an XI mutant showing higher activity at $\mathrm{pH}$ around 5 is required to enhance extracellular conversion of xylose to xylulose during yeast fermentation. For this purpose, we first compared the growth of transformants secreting XI at various $\mathrm{pH}$ conditions. To clarify the XI-dependent growth on xylose medium, S. cerevisiae $2805 \Delta$ gal80 strain was used for expression of TFP3-XI instead of the downstream pathway-amplified strain (S. cerevisiae 2805 $\Delta$ gal80, XKS1). S. cerevisiae $2805 \Delta$ gal80 strain was transformed with TFP3-XI expression vector, and equal number of cells were plated on the UDX solid medium ( $\mathrm{pH} \mathrm{3-7)} \mathrm{con-}$ taining $0.1 \%$ glucose and $2 \%$ xylose. A small amount of glucose was added to support the initial expression of recombinant XI. As shown in Additional file 1: Fig. S5, the transformant growth was seriously dependent on the media $\mathrm{pH}$. The number of transformed cells at $\mathrm{pH} 5$ was less than $3 \%$ of cells at $\mathrm{pH} 6$, and fewer colonies were formed at $\mathrm{pH}$ 4. This condition (UDX, $\mathrm{pH} 4$ ) was used to screen low-pH optimized XI. Random mutations were generated into the XI gene ( $x y l A)$ by error-prone PCR. Recombinant S. cerevisiae $2805 \Delta$ gal80 strains expressing XI mutant library were directly constructed by co-transformation of the PCR-amplified XI gene and linearized YGaTFP3 vector. Approximately $4 \times 10^{4}$ transformants $\left(2 \times 10^{3}\right.$ transformants $\times 20$ plates $)$ were screened on UDX solid media ( $\mathrm{pH} 4.0$ ), and hundreds of early formed colonies were transferred to 96 deep-well plates containing YPX broth ( $\mathrm{pH} 4.0)$. Seven rapidly growing cells were selected and confirmed again by cultivation in shake flask containing $50 \mathrm{~mL}$ YPX ( $\mathrm{pH}$ 4.0). The directed evolution process is summarised in Additional file 1: Fig. S6. Finally, a strain showing $36 \%$ and $20 \%$ enhanced xylose consumption and growth, respectively, compared to those of wild type, was selected, and the XI nucleotide sequence was determined. This mutant was named XI-76 according to the clone number. The XI-76 mutant contains two amino acid changes (E56A, I252M). To verify the effects of these mutations on XI activity, two mutants (XI-E56A, XI-I252M) each containing a single amino acid change were constructed. Three strains harbouring these mutations, along with the wild type, were cultured in flasks containing $50 \mathrm{~mL}$ YPX medium for $72 \mathrm{~h}$. The amounts of XI secreted during fermentation were compared by SDS-PAGE, and the optimum $\mathrm{pH}$ of the mutant XIs was analysed using $72 \mathrm{~h}$ culture supernatants (Fig. 5). While there was no significant difference of secreted XI yield between the mutants and wild type, a clear difference was observed in the optimum $\mathrm{pH}$. Between the two single mutants, only XI-E56A showed a change of optimum $\mathrm{pH}$ to $\mathrm{pH}$ 6. However, the optimum $\mathrm{pH}$ of the double mutant, XI-76, was synergistically changed to $\mathrm{pH}$ 5 by incorporation of the I252M mutation. Cell growth and xylose consumption of the strains expressing the single mutant XIs were increased by approximately $10 \%$ and further increased in XI-76 by over $20 \%$ compared to those in wild type (Table 1 ). To compare the relative activities of wild-type XI and XI-76 in different $\mathrm{pH}$ conditions, the two proteins were purified and specific activities of the purified XIs were analysed (Fig. 5c). Similar to the result obtained using crude $\mathrm{XI}$, the optimum $\mathrm{pH}$ of purified XI-76 was changed to $\mathrm{pH} 5$, and the relative activity of XI-76 was twofold higher than that of the wildtype $\mathrm{XI}$ at $\mathrm{pH}$ 5. The maximum activity of XI-76 at $\mathrm{pH}$ 5 was also $20 \%$ higher than that of wild-type XI at $\mathrm{pH}$ 7. Consequently, XI-76 could be useful for extracellular conversion of xylose to xylulose under the culture conditions of yeast $S$. cerevisiae.

\section{Low-pH optimized XI for xylose fermentation and glucose/ xylose co-fermentation}

To test the effect of low-pH optimized XI secretion on xylose fermentation and glucose/xylose co-fermentation, we employed a previously developed strain, S. cerevisiae SR8 which attained substantially improved xylose fermentation capability by optimisation of the expression 


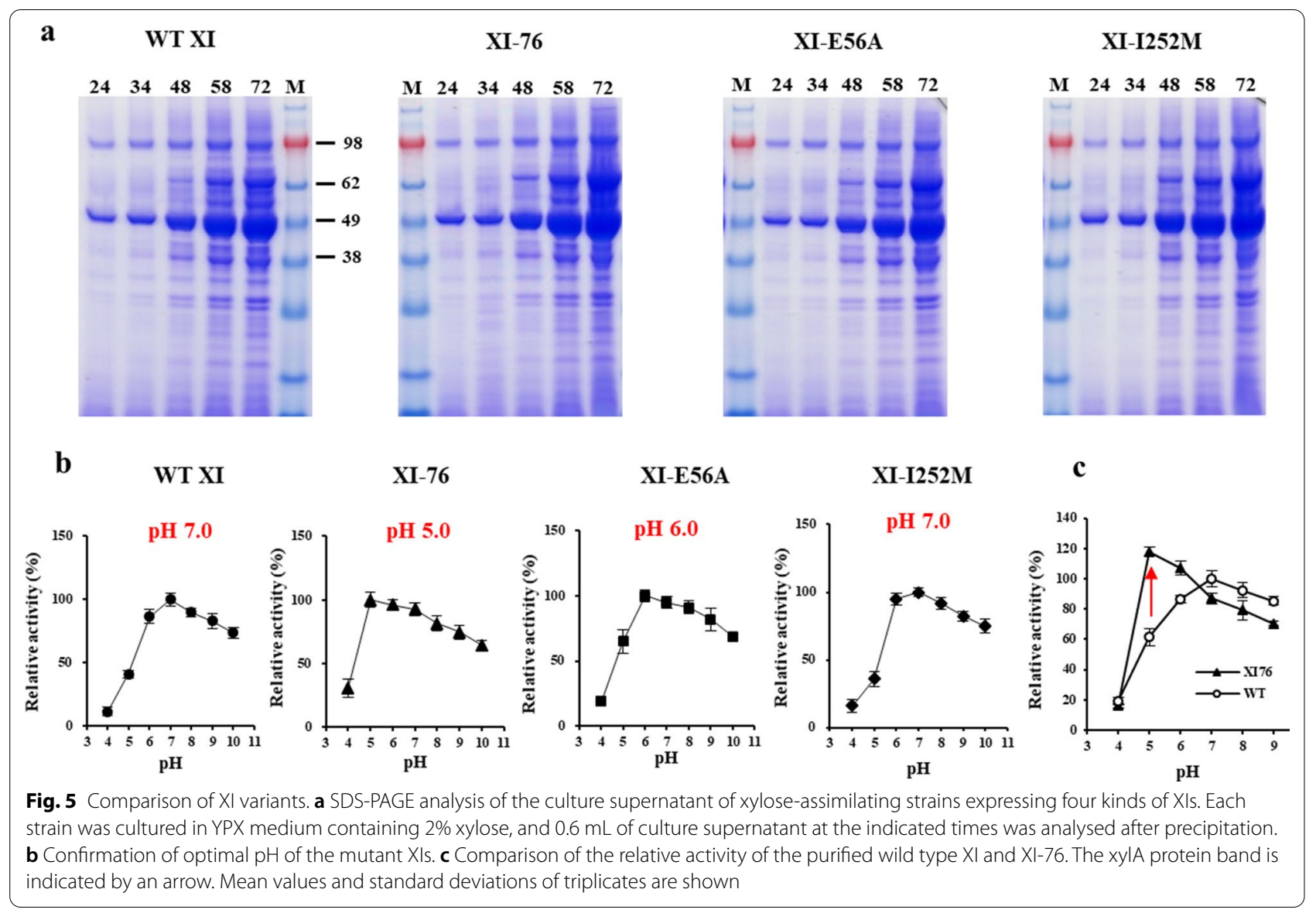

Table 1 Cell growth and xylose consumption of strains expressing different xylose isomerase (XI) variants

\begin{tabular}{lllcl}
\hline Strain & Mutations & Growth $\left(\mathbf{O D}_{600}\right)$ & Consumed xylose $(\mathbf{g})$ & Optimal pH \\
\hline WT & - & $15.3 \pm 0.5$ & $9.0 \pm 0.3$ & 7.0 \\
XI-76 & E56A, 1252M & $18.6 \pm 0.7$ & $13.4 \pm 0.5$ & 5.0 \\
XI-E56A & E56A & $16.5 \pm 0.5$ & $10.8 \pm 0.4$ & 6.0 \\
XI-I252M & I252M & $16.3 \pm 0.4$ & $10.6 \pm 0.4$ & 7.0 \\
\hline
\end{tabular}

Data shown represent the mean from triplicate experiments \pm SD

levels of $X Y L 1, X Y L 2$, and $X Y L 3$, and disruption of PHO13 and ALD6 [28]. There was an obvious improvement of xylose consumption and ethanol yield of $S$. cerevisiae 2805 $\Delta$ gal80, XKS1 strain when low-pH optimized XI was secreted, unfortunately, however, the final titer of ethanol was much lower than that of SR8 strain. Thus, we decided to introduce the low-pH optimized XI into the SR8 strain and checked the effect of XI secretion for the further improvement of xylose fermentation and glucose/xylose co-fermentation. Three strains expressing intra-XI, TFP3-XI, and TFP3-XI-76 under the control of GAPDH promoter and a strain containing the empty vector (pGAP) were cultured in YPX medium containing $8 \%$ xylose for $48 \mathrm{~h}$. As shown in Fig. 6, the intracellular expression of XI increased xylose consumption and ethanol production by approximately $7-8 \%$ compared to the SR8 strain harbouring the empty vector. Meanwhile, a $12-13 \%$ increase in the xylose consumption and ethanol production was achieved by secretion of wild-type XI, and further increased over $20 \%$ by secretion of the XI-76 mutant. For the glucose/xylose co-fermentation, these strains were cultured in YPDX medium containing $6 \%$ glucose and $8 \%$ xylose (Fig. 7 ). As a result of co-fermentation for $85 \mathrm{~h}$, glucose was rapidly consumed within 

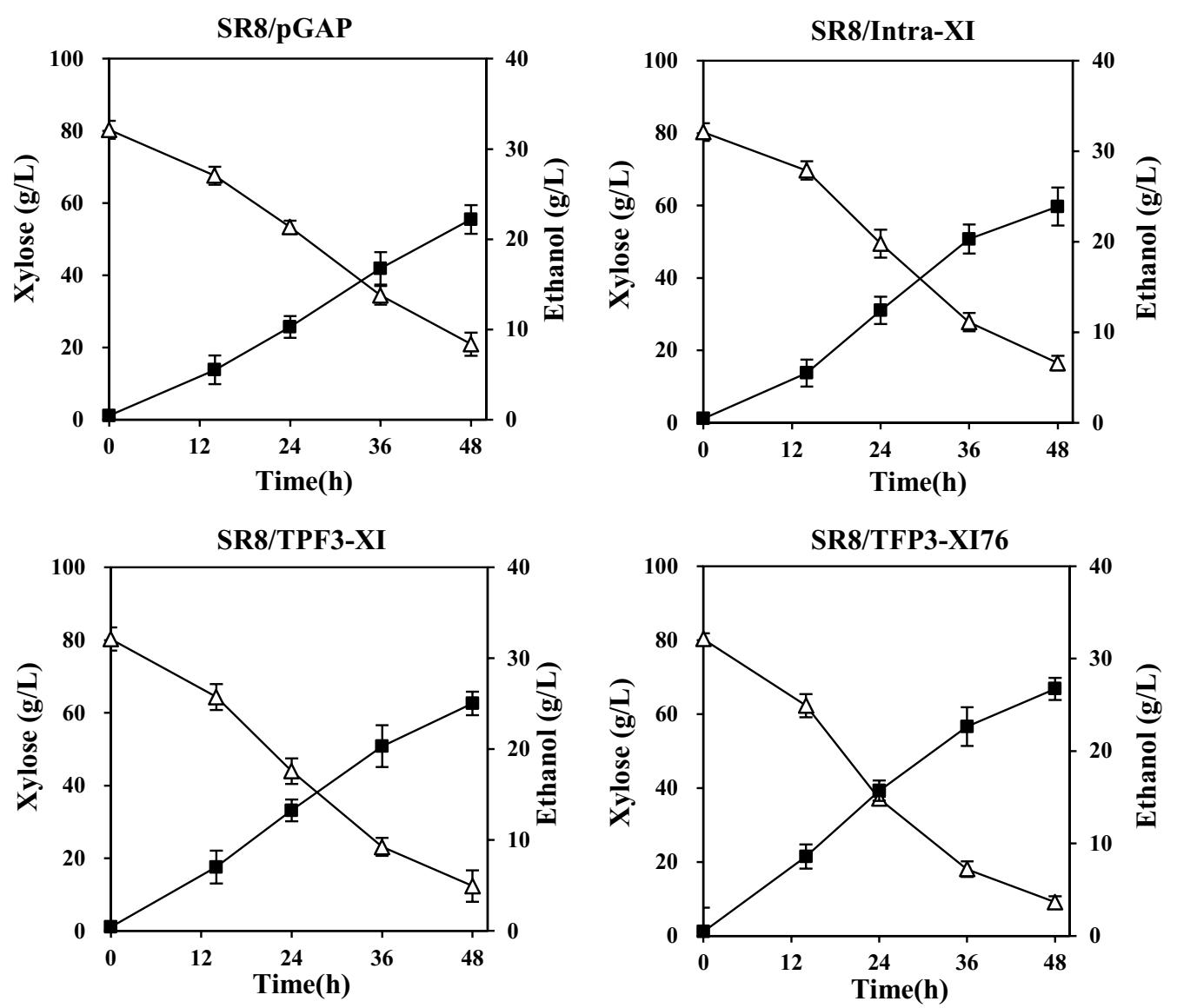

\begin{tabular}{lcccc}
\hline Strains & $\begin{array}{c}\text { Culture } \\
\text { time(H) }\end{array}$ & $\begin{array}{c}\text { Xylose } \\
\text { consumption } \\
\mathbf{( g / L )}\end{array}$ & $\begin{array}{c}\text { Ethanol } \\
\text { production } \\
\mathbf{( g / L )}\end{array}$ & $\begin{array}{c}\text { Yield } \\
\text { (EtOH/Xyl) }\end{array}$ \\
\hline SR8/pGAP & 48 & $59.4 \pm 0.2$ & $22.2 \pm 03$ & 0.37 \\
SR8/Intra-XI & 48 & $63.8 \pm 0.5$ & $23.9 \pm 0.4$ & 0.37 \\
SR8/TFP3-XI & 48 & $67.9 \pm 0.3$ & $25.0 \pm 0.4$ & 0.36 \\
SR8/TFP3-XI76 & 48 & $71.2 \pm 0.6$ & $26.7 \pm 0.2$ & 0.37 \\
\hline
\end{tabular}

Fig. 6 Fermentation profiles of xylose-assimilating strains expressing different XIs and an empty vector. YPX medium containing 8\% xylose was used as fermentation medium. Mean values and standard deviations of triplicates are shown. Symbols: Xylose ( $\triangle$ ), Ethanol

$15 \mathrm{~h}$ in all strains, and the initial xylose consumption rate was insignificant between the strains, but showed a difference from $24 \mathrm{~h}$ when sufficient XI was secreted. The overall xylose consumption was slightly reduced compared to the case of using xylose alone, but a similar improvement was confirmed when XI-76 was secreted. Consequently, secretory expression of low-pH optimized XI-76 improved the xylose consumption and ethanol production of the strain SR8 by approximately $7 \%$ and $15 \%$ from the co-fermentation of glucose and xylose. The final ethanol yield of glucose/xylose co-fermentation was also improved from $0.37 \mathrm{~g} / \mathrm{g}$ of SR 8 to $0.41 \mathrm{~g} / \mathrm{g}$ under the xylitol yield of $0.1 \mathrm{~g} / \mathrm{g}$ xylose.

\section{Discussion}

In this study, we developed a recombinant $S$. cerevisiae hyper-secreting XI from Piromyces sp. E2 using the TFP screening system [36] for the extracellular conversion of xylose to xylulose. For the effective secretion of a cytosolic protein-like XI, a powerful secretion leader that 

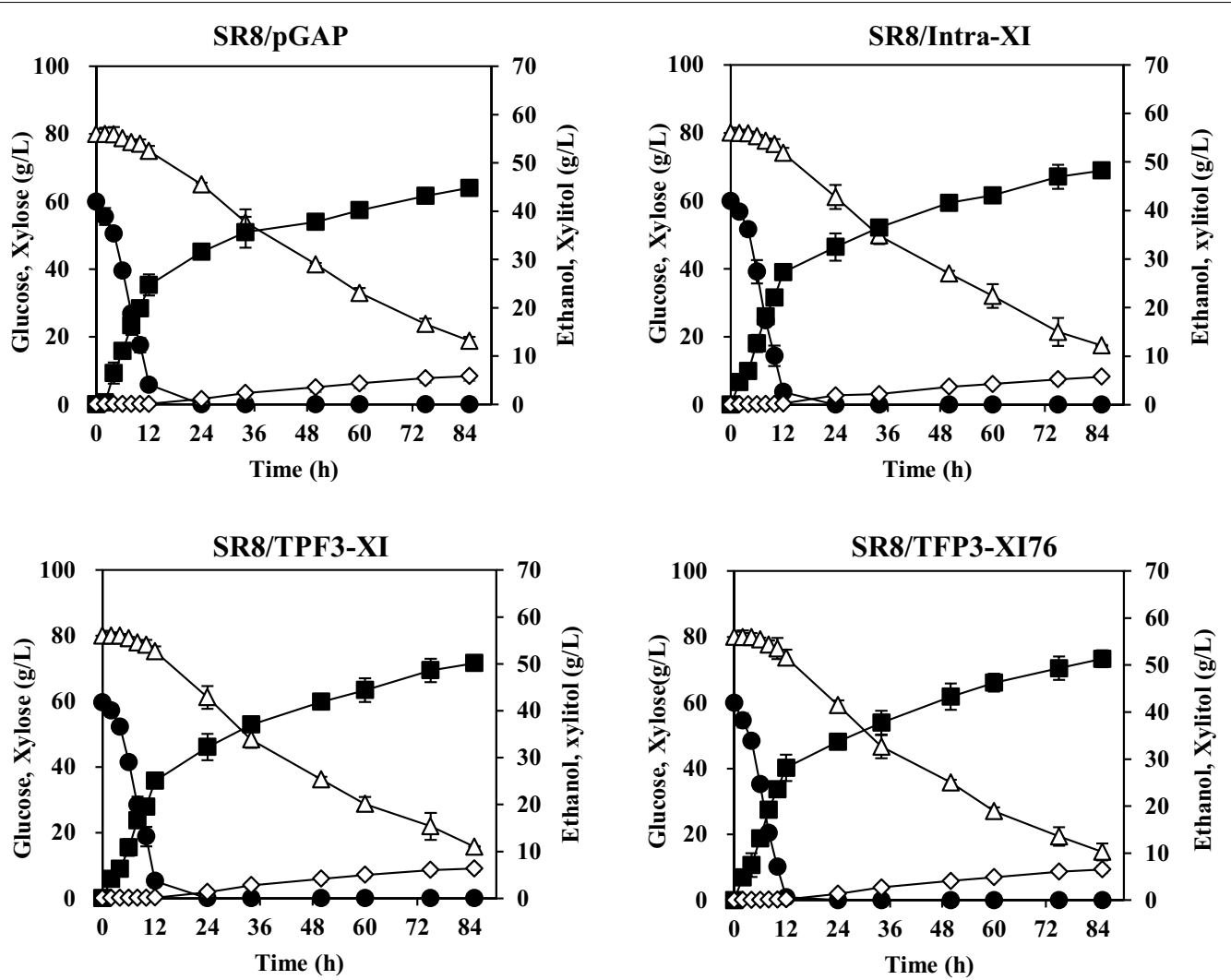

\begin{tabular}{lcccccc}
\hline \multicolumn{1}{c}{ Strains } & $\begin{array}{c}\text { Culture } \\
\text { time(H) }\end{array}$ & $\begin{array}{c}\text { Glucose } \\
\text { Consumption } \\
\mathbf{( g / L )}\end{array}$ & $\begin{array}{c}\text { Xylose } \\
\text { Consumption } \\
\mathbf{( g / L )}\end{array}$ & $\begin{array}{c}\text { Ethanol } \\
\text { Production } \\
(\mathbf{g} / \mathbf{L})\end{array}$ & $\begin{array}{c}\text { Xylitol } \\
(\mathbf{g} / \mathbf{L})\end{array}$ & $\begin{array}{c}\text { Yield } \\
(\mathbf{E t h a n o l} / \\
\text { sugar) }\end{array}$ \\
\hline SR8/pGAP & 85 & $60 \pm 0.8$ & $61.2 \pm 1.2$ & $44.8 \pm 0.8$ & $5.8 \pm 0.7$ & 0.370 \\
SR8/Intra-XI & 85 & $60 \pm 0.8$ & $62.6 \pm 0.2$ & $48.2 \pm 1.2$ & $5.8 \pm 0.8$ & 0.394 \\
SR8/TFP3-XI & 85 & $60 \pm 0.8$ & $64.3 \pm 0.2$ & $50.1 \pm 1.2$ & $6.3 \pm 0.4$ & 0.404 \\
SR8/TFP3-XI76 & 85 & $60 \pm 0.8$ & $65.3 \pm 2.6$ & $51.3 \pm 1.8$ & $6.5 \pm 0.8$ & 0.410 \\
\hline
\end{tabular}

Fig. 7 Co-fermentation profiles of xylose-assimilating strains expressing different XIs and an empty vector. YPDX medium containing $6 \%$ glucose and $8 \%$ xylose was used as fermentation medium. Mean values and standard deviations of triplicates are shown. Symbols: Glucose $(\mathbf{\bullet})$, Xylose $(\triangle)$, Ethanol $(\boldsymbol{\square})$, and Xylitol $(\diamond)$

drives a cargo protein into the secretion pathway is generally required. Yeast TFP library was generated from a genetic pool of yeast secretion proteins, which are composed of a signal peptide and a pro-peptide acting as secretion enhancer by assisting the folding and trafficking of cargo proteins. Among the 24 TFPs tested, TFP3 showed the highest level of XI secretion. TFP3 consists of 117 aa of the $\mathrm{N}$-terminus of the CIS3 protein. CIS3 has a pre-pro type secretion signal processed by Kex2p. The secretion signal of CIS3 has been used as a fusion partner for the production of xylanase and lipase in S. cerevisiae $[37,38]$. TFP3 induced the secretion of twice the amount of XI than that achieved using the MFo signal peptide, which is the most effective and popular pre-pro signal peptide in yeast.

When the cell growth and xylose consumption of the strain expressing TFP3-XI were compared with those of the strains expressing MF $\alpha$-XI and intra-XI in xylose medium, the TFP3-XI strain showed $40 \%$ enhanced cell growth and xylose consumption compared to the MFo-XI strain (Fig. 2a, b), and the intra-XI strain was slightly less effective than the TFP3-XI strain. The extracellular and total XI activities of the TFP3-XI strain were 2.6- and 3.2-fold higher than that of the MF $\alpha-X I$ 
strain, respectively. This is considered to have caused the enhanced cell growth and xylose consumption of TFP3XI. Meanwhile, the intra-XI strain showed twofold higher XI activity than TFP3-XI, but cell growth and xylose consumption were rather poor compared to TFP3-XI, demonstrating that the extracellular conversion of xylose to xylulose is more effective for xylose utilization. These results are consistent with previous reports that $S$. cerevisiae takes up xylulose better than xylose (21).

XIs have been divided into class I and class II enzymes based on their structure and metal ion preference. Piromyces XI expressed in E. coli was reported to show higher preference for $\mathrm{Mn}^{2+}$ compared to $\mathrm{Mg}^{2+}\left(29 \%\right.$ of $\left.\mathrm{Mn}^{2+}\right)$, and consequently classified into class II [33]. However, the XI produced in this study showed a slightly higher preference for $\mathrm{Mg}^{2+}$ than $\mathrm{Mn}^{2+}$ (Fig. 3c). This difference could be due to the concentration of the metal ions used. The relative activity of XI expressed in E. coli was analysed at a metal ion concentration of $100 \mu \mathrm{M}$, while the XI expressed in yeast was analysed at 100-fold higher concentrations of the metal ions $(10 \mathrm{mM})$. When these two ions were used simultaneously, a growth-improving synergy was identified at $0.5 \mathrm{mM} \mathrm{MnCl} 2$ and $20 \mathrm{mM}$ $\mathrm{MgCl}_{2}$.

Optimum temperature and $\mathrm{pH}$ of the recombinant XI secreted from $S$. cerevisiae in this study were found to be $60{ }^{\circ} \mathrm{C}$ and $\mathrm{pH} 7-8$, similar to those reported for most XI at $60{ }^{\circ} \mathrm{C}$ and pH 7-9, respectively [39]. Most studies on $\mathrm{XI}$ expression in S. cerevisiae for xylose assimilation have focused on cytosolic expression. As the cytosolic $\mathrm{pH}$ of S. cerevisiae is slightly below 7 , the activity of intracellular XI is usually optimal [11]. However, as found in this study, XI activity rapidly decreased at acidic $\mathrm{pH}$, with only $50 \%$ activity under the yeast culture condition $(\mathrm{pH}$ 5) compared to that at its optimal condition. Therefore, to enhance the extracellular conversion of xylose to xylulose under the yeast culture condition, the optimal pH of XI was shifted to near 5 by directed evolution. A variant xylA (XI-76) conferring enhanced xylose consumption and growth of host strain in xylose medium at $\mathrm{pH} 4$ was selected. Two amino acid substitutions (E56A, I252M) identified in this mutant were verified to contribute to the shift in optimal $\mathrm{pH}$ of XI and work synergistically. The shift in optimal $\mathrm{pH}$ mainly resulted from the E56A mutation and was enhanced by the I252M mutation. The XI-76 variant exhibited a twofold increase of the specific activity at $\mathrm{pH} 5$, and the maximum activity of XI-76 variant at $\mathrm{pH} 5$ was over $20 \%$ higher than that of wild-type $\mathrm{XI}$ at $\mathrm{pH}$ 7. This suggested that the mutations identified in XI-76 changed the optimum $\mathrm{pH}$ and increased the specific activity of XI simultaneously. Directed evolution of Piromyces sp. XI has been previously attempted to improve xylose fermentation in S. cerevisiae [40, 41].
In the former study, two amino acids located near the monomer binding contacts (E15D) and the active site (T142S) were shown to be responsible for the improved XI performance, while in the latter, substitution of residues around the substrate- and metal-binding sites was explored. Although the mutations identified in the current study were not directly related to the active site, the E56A mutation clearly affected the optimal pH of XI-76 mutant. Previously, homo-tetrameric structure of Piromyces sp. E2 XI was determined [33] and E56 was identified on the monomer binding contact surface. When the Glu (pI 3.08) is changed to Ala (pI 6.11), the net charge of this residue is changed to positive at $\mathrm{pH} 5$. Therefore, it can be inferred that positive charge at the 56th residue is more desirable for formation of multimeric XI or alterations in monomer interactions may affect substrate binding. A similar shift in the $\mathrm{pH}$ profile by modifying surface amino acids has been demonstrated in subtilisin [42].

To verify additional improvement of xylose fermentation, we introduced the low-pH optimized XI in a previously developed xylose-fermenting yeast $S$. cerevisiae SR8 [28, 43]. Secretory expression of XI-76 increased xylose consumption and ethanol yield by up to $20 \%$ and $12 \%$ compared to those of SR8 and SR8 strain expressing intracellular XI in YPX medium containing $8 \%$ xylose, respectively. Moreover, similar improvement was obtained with co-fermentation of glucose and xylose. Thus, xylose fermentation was definitely enhanced by the secretion of evolved XI through the extracellular conversion of xylose to xylulose. Our strain demonstrated a higher ethanol yield from mixed sugars $(0.41 \mathrm{~g} / \mathrm{g})$ than the reported strains harbouring combined $\mathrm{XR} / \mathrm{XDH}$ and XI pathways $(0.34-0.35 \mathrm{~g} / \mathrm{g})[17,18]$. Nevertheless, it is still far from the theoretical maximum yield of $0.51 \mathrm{~g} / \mathrm{g}$. As previously reported, the formation of xylitol must be a reason for lowering the ethanol yield, but as confirmed in this study, the xylitol yield was not serious at around $0.1 \mathrm{~g} / \mathrm{g}$ xylose. Accordingly, further optimization of other conditions will be required for the improvement of ethanol yield from xylose. Adaptive evolution of the current strain in different concentrations of glucose and xylose is also underway to enhance the ethanol yield. In addition, further improvement of ethanol yield could be expected by development of a mesophilic XI for yeast fermentation or by employing prokaryotic xylA gene from Clostridium phytofermentans, which was shown to perform better than Piromyces sp. XI [18].

\section{Conclusion}

In this study, we engineered the XI from Piromyces sp. E2 to shift its $\mathrm{pH}$ optimum to favour better xylose utilization under the acidic culture conditions used for yeast fermentation. Xylose was rapidly converted into xylulose 
during fermentation through the low-pH optimized extracellular XI to facilitate influx into the cell. Secretory expression of the engineered XI-76 variant in S. cerevisiae increased xylose consumption and ethanol production by approximately $7-20 \%$ and $15-20 \%$ in xylose fermentation and glucose and xylose co-fermentation, respectively. The low-pH optimized XI secretion system developed in this study could lay a foundation for the utilization of xylose or glucose/xylose obtained from lignocellulogic biomass.

\section{Materials and methods}

\section{Strains and plasmids}

Escherichia coli DH5 $\alpha$ [F-lacZA M15 hsdR17(r-m-) gyrA36] was used for general recombinant DNA techniques. S. cerevisiae 2805 4 gal80 (Mat a pep4::HIS3 prb1, can1, his3-200, gal80) [35] and S. cerevisiae SR8 (MATa, leu2, his3, ura3, can1, XYL1, XYL2, XKS1, evolutionarily engineered in xylose-containing media, ald6) [28] were used as general hosts for expression of XI. $S$. cerevisiae 2805 gal 80, XKS1 containing multi-copy integrated XKS1 under the control of glyceraldehyde 3-phosphate dehydrogenase (GAPDH) promoter was used for the directed evolution of XI. For multi-copy integration of the XKS1 gene into S. cerevisiae 2805 Agal80, plasmid $\delta I S X K$ donated by Prof. J. H. Seo was used [44]. For the construction of the pGAP-T3-xylA plasmid, GAL10 promoter of YGaT3xylA was replaced with the GAPDH promoter amplified with GAP-F/GAP-R primers (forward 5'-AGAGCTCGGTACCCATCAAGCTTACCA GTTCTCACAC-3' and reverse 5'-AGGATCCGTTTG TTTATGTGTGTTTATTCGA-3') after digestion with Sacl/BamHI. For construction of the pGAP-xylA plasmid, $x y l A$ gene amplified using intraXI-F (5'-AGGATC CATGGCAAAGGAATA- $\left.3^{\prime}\right)$ and intraXI-R primers $\left(5^{\prime}-\right.$ AGTCGACTTAGTGATGGTGAT-3') was digested with BamHI/SalI and then cloned into the same site of pGAPT3-xylA vector.

\section{Culture and analysis of secreted proteins}

Yeast transformation was performed using the lithium acetate method [45]. Yeast was aerobically cultivated at $30^{\circ} \mathrm{C}$ in synthetic defined medium lacking uracil (SD-ura; $0.67 \%$ yeast nitrogen base without amino acid, $2 \%$ glucose, $0.77 \mathrm{~g} / \mathrm{L}$-uracil dropout supplement, and $2 \%$ agar) for selection of transformants. YPD medium (1\% Yeast Extract, 2\% Peptone and 2\% glucose), YPX medium (1\% Yeast Extract, 2\% Peptone, $2 \%$ xylose, $0.5 \mathrm{mM} \mathrm{MnCl}_{2}$ and $20 \mathrm{mM} \mathrm{MgCl}$ ), and YPDX medium (1\% Yeast Extract, $2 \%$ Peptone, $1 \%$ glucose, $1 \%$ xylose, $0.5 \mathrm{mM} \mathrm{MnCl}_{2}$, and $20 \mathrm{mM} \mathrm{MgCl} 2$ ) were used for the expression of XI. UDX medium $(0.67 \%$ yeast nitrogen base without amino acid, $0.77 \mathrm{~g} / \mathrm{L}$-uracil dropout supplement, $0.1 \%$ glucose, $2 \%$ xylose, $1 \mu \mathrm{g} / \mathrm{mL}$ antimycin) was used for the selection of transformants in directed evolution of XI. Transformants were cultivated in a $10-\mathrm{mL}$ test tube containing $2 \mathrm{~mL}$ YPD broth for $40 \mathrm{~h}$. Then, $0.6 \mathrm{~mL}$ of culture supernatant was precipitated with $0.4 \mathrm{~mL}$ cold acetone and analysed by electrophoresis on $12 \%$ polyacrylamide gels under denaturing conditions by staining with Coomassie blue. Western blot analysis was performed using anti-His antibody (Sigma Chemicals Co., St. Louis, MO, USA) after 1:1000 dilution. Protein samples were electrophoresed and transferred to a nitrocellulose membrane using iBot ${ }^{\circledR} 2$ Dry Blotting System (Thermo Fisher Scientific, Waltham, MA, USA) following the manufacturer's instructions. The reacting antibodies were detected with anti-mouse immunoglobulins conjugated to alkaline phosphatase (Sigma Chemicals Co.)

\section{Construction of recombinant yeast secreting XI}

The nucleotide sequence of $x y l A$ from Piromyces sp. E2 (CAB76571.1) was codon-optimised using the codon optimisation tool from the IDT website (http://www. idtdna.com/CodonOpt), and overlapping sequences for recombinational cloning were added to the $5^{\prime}$ and $3^{\prime}$ ends of the optimised $x y l A$ gene. The optimised $x y l A$ gene was synthesized by Bioneer (Daejeon, Korea). The xylA gene was amplified with primers (forward LNK39 5'-GGC CGCCTCGGCCTCTGCTGGCCTCGCCTTAGATAA AAGA- ${ }^{\prime}$ and reverse GT50R 5'-GTCATTATTAAATAT ATATATATATATAT TGTCACTCCG TTCAAG TCG $\mathrm{AC}-3^{\prime}$ ) to expand the overlapping sequences as described previously [27]. Recombinant S. cerevisiae 2805 4 gal80 strains expressing $x y l A$ gene with TFPs were directly constructed by co-transformation of the amplified $x y l A$ gene and 24 linearized TFP vectors (Additional file 1: Fig. S1). Circular topology of the plasmid was restored in host cells by homologous recombination of a linearized TFP vector with $x y l A$ gene containing overlapping sequences at each end [46].

\section{Production and characterisation of XI}

Fed-batch fermentation was carried out in a 5-L fermenter (KoBiotech Co., Incheon, Korea). Seed culture for fermentation was prepared in a 250-mL Erlenmeyer flask containing $50 \mathrm{~mL}$ of SD-ura broth at $30^{\circ} \mathrm{C}$. After $24 \mathrm{~h}$ growth, the seed culture was transferred into $250 \mathrm{~mL}$ YPD broth to prepare the pre-culture. After $24 \mathrm{~h}$ growth, the pre-culture was inoculated into a 5 -L jar fermenter containing $1.8 \mathrm{~L}$ main culture medium ( $2 \%$ glucose, $3 \%$ yeast extract, and $1.5 \%$ peptone). The culture conditions were $30{ }^{\circ} \mathrm{C}$ and $\mathrm{pH} 5.5$ maintained by $\mathrm{NH}_{4} \mathrm{OH}$. During fermentation, the feeding medium $(300 \mathrm{~g} / \mathrm{L}$ of glucose and $50 \mathrm{~g} / \mathrm{L}$ of yeast extract) was added to maintain the concentration of the glucose. The cell mass and secreted protein were analysed by optical density $\left(\mathrm{OD}_{600}\right)$ and 
SDS-PAGE, respectively. The culture supernatant was filtered with 0.2- $\mu \mathrm{m}$ Sartoclear ${ }^{\circledR}$ S9-P Cap (Sartorius AG, Göttingen, Germany) and concentrated tenfold by ultrafiltration with a $30 \mathrm{~K}$ NMWC pore size filter (GE Healthcare, Chicago, IL, USA) and $20 \mathrm{mM}$ Tris- $\mathrm{HCl}$ (pH 7.5) buffer. The concentrated protein was applied onto an Ni-NTA affinity chromatography column (GE Healthcare) pre-equilibrated with buffer A $[20 \mathrm{mM}$ Tris- $\mathrm{HCl}$ ( $\mathrm{pH} 7.5)$ and $0.5 \mathrm{M} \mathrm{NaCl}]$. After washing with the washing buffer $[20 \mathrm{mM}$ Tris- $\mathrm{HCl}$ (pH 7.5), $0.5 \mathrm{M} \mathrm{NaCl}$, and $20 \mathrm{mM}$ imidazole], the bound proteins were eluted with buffer B [20 mM Tris- $\mathrm{HCl}$ (pH 7.5), $0.5 \mathrm{M} \mathrm{NaCl}$, and $250 \mathrm{mM}$ imidazole]. The eluted protein was concentrated using an Amicon ultra centrifugal filter and $20 \mathrm{mM}$ Tris$\mathrm{HCl}$ (pH 7.5) buffer. The optimum $\mathrm{pH}$ of the purified XI was measured at $60{ }^{\circ} \mathrm{C}$ using $\mathrm{pH} \mathrm{3-11}$ buffers (pH 3-6: $50 \mathrm{mM}$ citrate buffer, $\mathrm{pH}$ 6-7: $50 \mathrm{mM}$ potassium phosphate buffer, $\mathrm{pH}$ 7-11: Tris- $\mathrm{HCl}$ buffer), and the optimum temperature was determined in $50 \mathrm{mM}$ Tris- $\mathrm{HCl}$ buffer $(\mathrm{pH} 7.5)$ at various temperatures $\left(20 \sim 80^{\circ} \mathrm{C}\right)$.

To determine the effect of various metal ions on XI activity, $10 \mathrm{mM}$ of various metal ion chlorides (cobalt, magnesium, manganese, cupper, calcium, barium, zinc) and ethylene diamine tetra acetic acid were pre-incubated with the enzyme solution in $50 \mathrm{mM}$ Tris- $\mathrm{HCl}$ buffer (pH 7.5) for $15 \mathrm{~min}$. After incubation, the enzyme activity was analysed at optimum condition; XI activity of the enzyme without metal ions was set to $100 \%$. XI activity was analysed in a solution containing $50 \mathrm{mM}$ Tris- $\mathrm{HCl}$ (pH 7.5), $10 \mathrm{mM} \mathrm{MgCl}_{2}$, and $1 \mathrm{mg}$ of purified enzyme. After addition of $10 \%$ xylose, the reaction mixture was incubated at $60{ }^{\circ} \mathrm{C}$ for $3 \mathrm{~h}$, and the reaction was stopped by addition of $0.1 \mathrm{M} \mathrm{NaOH}$. The amount of xylulose produced was determined by high-performance liquid chromatography (HPLC) analysis. One unit of XI activity was defined as the amount of enzyme required to produce $1 \mu \mathrm{mol}$ of xylulose per min under the assay conditions described above.

\section{Ethanol fermentation}

The seed culture was prepared by incubating XI strains in test tube culture containing $10 \mathrm{~mL}$ YPD broth for $24 \mathrm{~h}$ at $30{ }^{\circ} \mathrm{C}$ with shaking at $200 \mathrm{rpm}$. Oxygen-limited fermentation was performed at $30{ }^{\circ} \mathrm{C}$ and $200 \mathrm{rpm}$ in $125-\mathrm{mL}$ serum bottles closed with butyl rubber stoppers and then purged with $\mathrm{N}_{2}$ gas using $50 \mathrm{~mL}$ YP medium (1\% Yeast Extract, 2\% Peptone, $20 \mathrm{mM} \mathrm{MgCl}, 0.5 \mathrm{mM}$ $\mathrm{MnCl}_{2}$ ) with various concentrations of glucose and xylose $(2 \sim 10 \%$ glucose and $2 \sim 10 \%$ xylose). The initial cell density was adjusted to $\mathrm{OD}_{600}=5$, which was predetermined to be an optimal seed amount in a preliminary test. Glucose, xylose, xylulose, xylitol, and ethanol were analysed by HPLC and a refractive index detector
(Agilent Technologies, Santa Clara, CA, USA) with an Aminex HPX-87H column (Bio-Rad, Hercules, CA, USA). The column temperature was maintained at $65^{\circ} \mathrm{C}$, and $0.005 \% \mathrm{H}_{2} \mathrm{SO}_{4}$ was used as the mobile phase with a flow rate of $0.6 \mathrm{~mL} / \mathrm{min}$.

\section{Statistical analyses}

All data are represented as the mean value \pm standard deviation (SD) of three experiments. Statistical comparison of ethanol concentration, sugar utilized and growth were performed using the Student's $t$ test with a twotailed distribution (Microsoft Excel) and compared to the appropriate control strain. A $p$ value of $<0.05$ was considered statistically significant.

\section{Abbreviations}

TFP: Translational fusion partner; SIF: Simultaneous isomerization and fermentation; XI: Xylose isomerase; XR: Xylose reductase; $\mathrm{XDH}$ : Xylitol dehydrogenase; XK: Xylulose kinase.

\section{Supplementary Information}

The online version contains supplementary material available at https://doi. org/10.1186/s13068-021-02073-y.

\begin{abstract}
Additional file 1: Figure S1. Scheme for the direct construction of recombinant $x y / A$ expression vectors by in vivo recombination with translational fusion partners (TFPs). Figure S2. Optimal TFP screening for secretory expression of xylA. (a) SDS-PAGE analysis of culture broth of recombinant yeasts expressing $x y \mid A$ and Coomassie Blue staining. The xylA protein band was verified by western blotting analysis (b). 1-24; TFP number, M: protein size marker. Figure S3. Determination of optimal concentration of metal ions for growth in YPX medium containing $2 \%$ xylose as a sole carbon source. Various concentration of $\mathrm{MnCl}_{2}$ (a), $\mathrm{MgCl}_{2}$ (b) were analyzed separately and simultaneously (c). All experiment were triplicated and the results are given as mean values with error bars indicating standard deviations ${ }^{*} p<0.03$. Figure $\mathbf{S 4}$. Co-fermentation of glucose and xylulose using wild type (a) and xylulokinase overproduced strain (b). All experiment were triplicated and the results are given as mean values with error bars indicating standard deviations Symbols: Glucose ( $)$, Xylulose $(\triangle)$, Ethanol $(\boldsymbol{\square})$. Figure S5. Comparison of growing cells on different $\mathrm{pH}$ media after transformation of TFP3-XI vector. UDX solid media containing $0.1 \%$ glucose and $2 \%$ xylose with different $\mathrm{pH}$ from 3 to 7 were used. Figure S6. Summary of directed evolution of XI for the development of low-pH optimized XI.
\end{abstract}

\section{Authors' contributions}

$J H S$ and JHB designed the experiments. MJK engineered the yeast strains and analysed the ethanol production. BHS, YSJ, and JHS analyzed the data. JHB and JHS drafted the manuscript, which was edited by all authors. All authors read and approved the final manuscript.

\section{Funding}

This work was supported by the (i) Cooperative Research Program for Agriculture Science and Technology Development (PJ0149382021) through Rural Development Administration of Korea, (ii) Korea Health Technology R\&D Project through the Korea Health Industry Development Institute (KHIDI), funded by the Ministry of Health \& Welfare, Republic of Korea (HP20C0087), (iii) High Value-added Food Technology Development Program through the Korea Institute of Planning and Evaluation for Technology in Food, Agriculture and Forestry (IPET) funded by Ministry of Agriculture, Food and Rural Affairs (321026-5) and (iv) Research Initiative Program of KRIBB. 


\section{Availability of data and materials}

All data generated or analysed during this study are included in this published article and its Additional information files.

\section{Declarations}

\section{Ethics approval and consent to participate}

Not applicable.

\section{Consent for publication}

Not applicable.

\section{Competing interests}

The authors declare that they have no competing interests.

\section{Author details}

${ }^{1}$ Synthetic Biology and Bioengineering Research Center, Korea Research Institute of Bioscience and Biotechnology (KRIBB), 125 Gwahak-ro, Yuseong-gu, Daejeon 34141, Republic of Korea. ${ }^{2}$ Department of Food Science and Human Nutrition, University of Illinois at Urbana-Champaign, Urbana, IL 61801, USA. ${ }^{3}$ Cellapy Bio Inc., Bio-Venture Center 211, 125 Gwahak-ro, Yuseong-gu, Daejeon 34141, Republic of Korea.

Received: 10 September 2021 Accepted: 10 November 2021

Published online: 25 November 2021

\section{References}

1. Lennartsson PR, Erlandsson P, Taherzadeh MJ. Integration of the first and second generation bioethanol processes and the importance of byproducts. Bioresour Technol. 2014;165:3-8.

2. Park $\mathrm{H}$, et al. Xylose utilization in Saccharomyces cerevisiae during conversion of hydrothermally pretreated lignocellulosic biomass to ethanol. Appl Microbiol Biotechnol. 2020;104(8):3245-52.

3. Miura M, et al. Bioconversion of birch wood hemicellulose hydrolyzate to xylitol. Appl Biochem Biotechnol. 2015;176(3):947-55.

4. Veras HCT, Parachin NS, Almeida JRM. Comparative assessment of fermentative capacity of different xylose-consuming yeasts. Microb Cell Fact. 2017;16(1):153

5. Cunha JT, et al. Engineered Saccharomyces cerevisiae for lignocellulosic valorization: a review and perspectives on bioethanol production. Bioengineered. 2020;11(1):883-903.

6. Kato $\mathrm{H}$, et al. Cocktail delta-integration of xylose assimilation genes for efficient ethanol production from xylose in Saccharomyces cerevisiae. J Biosci Bioeng. 2013;116(3):333-6.

7. Guo J, et al. Heterologous expression of Spathaspora passalidarum xylose reductase and xylitol dehydrogenase genes improved xylose fermentation ability of Aureobasidium pullulans. Microb Cell Fact. 2018;17(1):64.

8. Zhang B, et al. Data for rapid ethanol production at elevated temperatures by engineered thermotolerant Kluyveromyces marxianus via the NADP(H)-preferring xylose reductase-xylitol dehydrogenase pathway. Data Brief. 2015:5:179-86.

9. Ko JK, et al. Ethanol production from lignocellulosic hydrolysates using engineered Saccharomyces cerevisiae harboring xylose isomerase-based pathway. Bioresour Technol. 2016;209:290-6.

10. Qi X, et al. Heterologous xylose isomerase pathway and evolutionary engineering improve xylose utilization in Saccharomyces cerevisiae. Front Microbiol. 2015:6:1165.

11. van Maris AJ, et al. Development of efficient xylose fermentation in Saccharomyces cerevisiae: xylose isomerase as a key component. Adv Biochem Eng Biotechnol. 2007;108:179-204.

12. Hoang Nguyen Tran P, et al. Improved simultaneous co-fermentation of glucose and xylose by Saccharomyces cerevisiae for efficient lignocellulosic biorefinery. Biotechnol Biofuels. 2020;13:12.

13. Karhumaa $\mathrm{K}$, et al. Comparison of the xylose reductase-xylitol dehydrogenase and the xylose isomerase pathways for xylose fermentation by recombinant Saccharomyces cerevisiae. Microb Cell Fact. 2007:6:5.
14. Li X, et al. Comparison of xylose fermentation by two high-performance engineered strains of Saccharomyces cerevisiae. Biotechnol Rep (Amst). 2016;9:53-6.

15. Kobayashi Y, et al. Systematic optimization of gene expression of pentose phosphate pathway enhances ethanol production from a glucose/xylose mixed medium in a recombinant Saccharomyces cerevisiae. AMB Express. 2018;8(1):139.

16. Jeong $D$, et al. Metabolic engineering considerations for the heterologous expression of xylose-catabolic pathways in Saccharomyces cerevisiae. PLoS ONE. 2020;15(7):e0236294.

17. Wang C, et al. Coutilization of D-Glucose, D-Xylose, and L-Arabinose in Saccharomyces cerevisiae by coexpressing the metabolic pathways and evolutionary engineering. Biomed Res Int. 2017;2017:5318232.

18. Cunha JT, et al. Xylose fermentation efficiency of industrial Saccharomyces cerevisiae yeast with separate or combined xylose reductase/ xylitol dehydrogenase and xylose isomerase pathways. Biotechnol Biofuels. 2019;12:20.

19. Kuyper $M$, et al. Metabolic engineering of a xylose-isomeraseexpressing Saccharomyces cerevisiae strain for rapid anaerobic xylose fermentation. FEMS Yeast Res. 2005:5(4-5):399-409.

20. Madhavan A, et al. Alcoholic fermentation of xylose and mixed sugars using recombinant Saccharomyces cerevisiae engineered for xylose utilization. Appl Microbiol Biotechnol. 2009;82(6):1037-47.

21. Chiang LC, et al. d-Xylulose fermentation to ethanol by Saccharomyces cerevisiae. Appl Environ Microbiol. 1981;42(2):284-9.

22. Chandrakant P, Bisaria VS. Simultaneous bioconversion of glucose and xylose to ethanol by Saccharomyces cerevisiae in the presence of xylose isomerase. Appl Microbiol Biotechnol. 2000;53(3):301-9.

23. Rao K, et al. A novel technique that enables efficient conduct of simultaneous isomerization and fermentation (SIF) of xylose. Appl Biochem Biotechnol. 2008;146(1-3):101-17.

24. Ota M, et al. Display of Clostridium cellulovorans xylose isomerase on the cell surface of Saccharomyces cerevisiae and its direct application to xylose fermentation. Biotechnol Prog. 2013;29(2):346-51.

25. Hess JM, et al. Thermotoga neapolitana homotetrameric xylose isomerase is expressed as a catalytically active and thermostable dimer in Escherichia coli. Appl Environ Microbiol. 1998;64(7):2357-60.

26. Kuyper $M$, et al. High-level functional expression of a fungal xylose isomerase: the key to efficient ethanolic fermentation of xylose by Saccharomyces cerevisiae? FEMS Yeast Res. 2003;4(1):69-78.

27. Bae $\mathrm{JH}$, et al. A novel fusion partner for enhanced secretion of recombinant proteins in Saccharomyces cerevisiae. Appl Microbiol Biotechnol. 2016;100(24):10453-61.

28. Kim SR, et al. Rational and evolutionary engineering approaches uncover a small set of genetic changes efficient for rapid xylose fermentation in Saccharomyces cerevisiae. PLOS ONE. 2013;8(2):57048.

29. Ko $\mathrm{H}$ et al. Efficient production of levan using a recombinant yeast Saccharomyces cerevisiae hypersecreting a bacterial levansucrase. J Ind Microbiol Biotechnol. 2019

30. $\mathrm{Ko} \mathrm{H}$, et al. Microbial production of medium chain fructooligosaccharides by recombinant yeast secreting bacterial inulosucrase. Enzyme Microb Technol. 2019;130:109364.

31. Lee CR, et al. Co-fermentation using recombinant Saccharomyces cerevisiae yeast strains hyper-secreting different cellulases for the production of cellulosic bioethanol. Sci Rep. 2017;7(1):4428.

32. Idiris $A$, et al. Engineering of protein secretion in yeast: strategies and impact on protein production. Appl Microbiol Biotechnol. 2010;86(2):403-17.

33. Lee $\mathrm{M}$, et al. Metal dependence of the xylose isomerase from Piromyces sp. E2 explored by activity profiling and protein crystallography. Biochemistry. 2017;56(45):5991-6005.

34. Fuxreiter $M$, et al. Role of electrostatics at the catalytic metal binding site in xylose isomerase action: $\mathrm{Ca}(2+)$-inhibition and metal competence in the double mutant D254E/D256E. Proteins. 1997;28(2):183-93.

35. Ahn J, et al. GAL promoter-driven heterologous gene expression in Saccharomyces cerevisiae Delta strain at anaerobic alcoholic fermentation. FEMS Yeast Res. 2013;13(1):140-2.

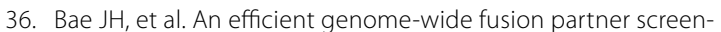
ing system for secretion of recombinant proteins in yeast. Sci Rep. 2015:5:12229. 
37. Andres I, et al. Use of the cell wall protein Pir4 as a fusion partner for the expression of Bacillus sp. BP-7 xylanase A in Saccharomyces cerevisiae. Biotechnol Bioeng. 2005;89(6):690-7.

38. Mormeneo M, et al. Efficient secretion of Bacillus subtilis lipase A in Saccharomyces cerevisiae by translational fusion to the Pir4 cell wall protein. Appl Microbiol Biotechnol. 2008;80(3):437-45.

39. Asboth B, Naray-Szabo G. Mechanism of action of D-xylose isomerase. Curr Protein Pept Sci. 2000;1(3):237-54.

40. Lee SM, Jellison T, Alper HS. Directed evolution of xylose isomerase for improved xylose catabolism and fermentation in the yeast Saccharomyces cerevisiae. Appl Environ Microbiol. 2012;78(16):5708-16.

41. Lee $M$, et al. Structure-based directed evolution improves S. cerevisiae growth on xylose by influencing in vivo enzyme performance. Biotechnol Biofuels. 2020;13:5.

42. Russell AJ, Fersht AR. Rational modification of enzyme catalysis by engineering surface charge. Nature. 1987;328(6130):496-500.
43. Wei N, et al. Enhanced biofuel production through coupled acetic acid and xylose consumption by engineered yeast. Nat Commun. 2013; $4: 2580$

44. Lee TH, et al. Effects of xylulokinase activity on ethanol production from D-xylulose by recombinant Saccharomyces cerevisiae. J Appl Microbiol. 2003;95(4):847-52.

45. Gietz D, et al. Improved method for high efficiency transformation of intact yeast cells. Nucleic Acids Res. 1992;20(6):1425.

46. Kunes $\mathrm{S}$, et al. Fine structure recombinational analysis of cloned genes using yeast transformation. Genetics. 1987;115(1):73-81.

\section{Publisher's Note}

Springer Nature remains neutral with regard to jurisdictional claims in published maps and institutional affiliations.
Ready to submit your research? Choose BMC and benefit from:

- fast, convenient online submission

- thorough peer review by experienced researchers in your field

- rapid publication on acceptance

- support for research data, including large and complex data types

- gold Open Access which fosters wider collaboration and increased citations

- maximum visibility for your research: over 100M website views per year

At BMC, research is always in progress.

Learn more biomedcentral.com/submissions 